\title{
Application of virtual Reality Technology in the Experimental Teaching of Machinery Manufacturing Simulation
}

\author{
Meng Yanmei ${ }^{1,}$, , Sun Qihui ${ }^{2, b}$, Li Xianwang ${ }^{3, c}$, Dong Zhen ${ }^{4, ~ d, ~ W a n g ~}$ \\ Xiaochun $^{5,}$, Tang Zhihong ${ }^{6, f}$ \\ ${ }^{1}$ National project in mechanical engineering virtual simulation experiment teaching center in \\ Guangxi University, Mechanical Engineering College in Guangxi Univercity, Nanning Guangxi, \\ China \\ ${ }^{2}$ Mechanical Engineering College in Guangxi Univercity, Nanning Guangxi, China \\ agxu_mengyun@163.com, b731393808@qq.com
}

Keywords: Virtual Reality, Machine Manufacturing, Immersion Type, Simulation Experiment, Large-scale Comprehensive Experiment

Abstract. Some virtual experiments, such as parts machining process, assembly process and digital workshop, are developed based on virtual reality. Learning environment of advanced manufacturing technology is constructed in virtual reality environment, which realizes every stage of production, including manufacturing, assemblying, quality controlling and detecting. This technology enables students to understand the production line, workshop, factory information delivery and real manufacturing vividly. What's more, it has broken up the difficulty to operate large scale comprehensive experiment project because of high cost, high consumption and venues, and also increased the students' learning interest greatly.

\section{Introduction}

Laboratories of colleges and universities as important bases to cultivate college students' innovation spirit and practice ability has become an important part of talent training link. Since the enrollment expansion of colleges and universities after 1999 and as the "211 project" and "985 project" construction project has been implemented, wholesale funding has been invested into the laboratory construction and the number and scale of laboratory has increased rapidly and the experiment teaching condition has been improved greatly. In recent years, with the constant improvement of the national requirements for the quality of higher education, this extensional development which relies on to increase the number of laboratory and expand the scale of the laboratory can't meet the needs of the society for innovative talent cultivation. With the deepening reform of higher education and limited equipment sites and teachers in the experiment teaching, the teaching mode which depends on the physical experiment entirely restricts the cultivation of students' innovative consciousness and innovation ability greatly[1,2.3,4,5]. There are following problems in the mechanical engineering experiment and practice teaching based on hardware operation:

Because mechanical material and related equipments are expensive and easy to wear , and the traditional mechanical engineering experiment exists teaching adaptability and real-time problems, conventional experiment teaching are susceptible to be restricted by experiment equipment, experiment space, experiment time and experiment content. 
Because of the limited experimental equipment and experiment operation containing certain risk, it will cause personnel injuries or equipment damages by any carelessness. Because a number of traditional experiments are operated by experimenters, students just observe the experiment phenomenon and record the experiment data, and have no chance to operate experiments to improve their practical ability personally. Because the experimental limitations are big and the effect of comprehensive and innovative experiments is bad, it is adverse to improve the students' interests of experiment and cultivate students' innovative consciousness.

The campus operation training is just a certain type of work almost, and the quality, cost, and delivery date requirements of Enterprises can't reflect, so students can not experience real enterprise working environment in the practice field. Students can only participate in a certain production process in off-campus practice, and can not experience all work steps of professional positions. The primary task of enterprises is production and enterprises do not pay attention to the cultivation of the students, so the effect of the student practice is limited greatly.

Virtual reality is a five-dimensional spacetime simulation of the real world, that means in addition to the simulation of three dimensional space and one dimensional time, there is another dimensional of simulation of natural interaction at the same time. Virtual reality can provide users with a variety of measurements, such as visual, auditory, tactile, etc at the same time[6,7]. Virtual machinery manufacturing experiment platform based on virtual reality provides an advanced and flexible experimental environment for teaching practice, so the classroom teaching is no longer confined to the physical space and limited equipment, and the method of teaching and learning has been extended invisibly. Through the construction of realistic experimental operating environment and experiment object, students can develop efficient, safe and economical experiments in the open, independent and interactive virtual environment, and then achieve the teaching effect which is difficult to achieve in real experiment.

\section{Content Settings of Virtual Machinery Manufacturing Simulation Experiment Teaching}

Operation of manufacturing enterprises involves three main lines, the development process, management process and manufacturing process. Therein the manufacturing process is the sum of all the manufacturing activities that are related to each other from the raw materials to the final product. Manufacturing process involves many aspects, such as process planning, production line layout, production arrangement, and so on. These factors affect the quality, efficiency and cost of manufacturing directly. Virtual mechanical manufacturing simulation experiment teaching covers foundation courses' experiments and professional courses' experiments. such as <Metalworking practice $>,<$ Fundamentals of Mechanical Manufacturing Technology $\rangle$, <Advanced manufacturing technology $\rangle$, <Computer integrated manufacturing $>$, <Special processing technology $>$, $<$ Mechanical CAD/CAM>, < NC programming > and so on. Virtual simulation experiment project is built from three levels of foundation, comprehensive, research-based in hardware and software experiments of virtual reality platform, virtual manufacturing system and digital factory simulation platform which we brought.

The Content of Virtual Machinery Manufacturing Simulation Experiment is Configured by the Step from Foundation to Comprehensiveness to Design to Research, the Step from Simple to Complex, the Step from Point to Surface, and the Step from Local to the Global.

Step of Learning from Point to Surface: Through simulating the work environment, working procedure and working contents of digital processing workshop of the main types realistically, students can experience all job skills of various types work positions immersingly. For example, a typical case of crank shaft parts processing process is raw-material to forge to cut to milling to 
assemble. Therefore students can learn all the process of machinery manufacturing which is from raw material to sheet metal processing to parts processing. Meanwhile all production process of machinery manufacturing enterprises is displayed by digital factory instance, all Phases of the simulation of manufacturing, assembly, quality control and testing in the production are achieved by virtual manufacturing technology. Students can learn the process of information tdelivery among production line, workshop and factories and process from design to the actual manufacturing easily. Students can learn process of a single type of work to parts complete machining independently and realistically in machinery manufacturing enterprises and has a skeleton of learning about the whole production process in the enterprise. Students' interests has been improved effectively, the cognition of manufacturing process and enterprise has been deepen, and the effect in virtual machinery manufacturing simulation experiment is better than it in actual site.

Step of Learning from Simple to Complex: Machining process and processing technology can be learned and grasped in virtual reality environment. For instance, operator put a blank of machining parts in virtual manufacturing environment, and cutting tool is simulated as lathe work and other types of machining. Then the system analyses of whether there is interference in cutting tool and workpiece, predicts processing results and adjusts and optimizes parameters of processing technology based on cutting tool's running situations and workpiece's cutting situations. Afterwards the simulation of NC machining is started in virtual NC machine tools and machining center, trajectory and parameters of cutting tool are described realistically, and the corresponding functions are competed. Students can use knowledge and skills to do virtual design, off-line programming and virtual manufacturing on virtual manufacturing platform computer in the course of internship. Students can show individual character, give full play to imagination and creativity, make one more scheme, analyze, compare and optimize on schemes in virtual environment. After the design and technology program which students developed has been affirmed, students can convert simulation results into instructions and send instructions to rapid prototyping equipment NC machine tools and machining center. Computer aided teaching practice system and the real manufacturing environment are combined felicitously, and the learning of manufacturing process and technology has been grasped gradually.

Step of Learning from Local to the Global: Virtual workshops and digital factories are built on virtual reality technique. Students can learn workshop layout and design and optimization of digital factories, and can be quite familiar with every stage of the simulation rehearsal method of manufacturing, assembly, quality control and testing in the process producing production using virtual manufacturing technology, can easily learn the process of information transmitted among production line, workshop and factories and process from design to the actual manufacturing. The determinacy from design to manufacture can be strengthen, the manufacturing process on a computer can be compressed and advanced, and the manufacturing process can be test by a computer, the success rate and reliability of enterprise production can be enhanced, and the conversion time from design to production can be shorten. Students can experience designs and optimization methods of all post work and production processes of real enterprise in virtual experiment environment they build.

\section{Cases of Virtual Simulation Experiment in Machinery Manufacturing Based on Virtual Reality Technology}

A Simulation Experiment for Manufacturing Process of a Large Marine Crankshaft. The crankshaft is an important part of the engine, which is subjected to impact load and power 
transmission. It is difficult to ensure the quality of processing of crankshafts in the five most important parts of engine. Because working conditions of the crankshaft is very bad, crankshaft material and machining technology, precision, surface roughness, heat treatment and surface hardening, dynamic balance, and etc are required to be very strict. If one of the links is not guaranteed, the service life of the crankshaft and the reliability of the whole machine will be seriously affected. Automobile industries of developed countries all over the world have attached great importance to the processing of the crankshaft, and continuously improve the machining process.

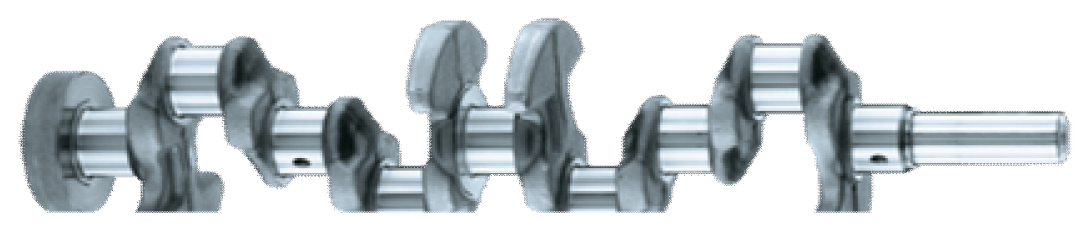

Fig. 1 crankshaft figure

Superficially, marine crankshaft is only a dozen tons of length mass with a piece of iron. However, its design and manufacturing process is quite complex. There are two manufacturing methods. One is the crankshaft of the whole, which is mainly used for small and medium ships and power generation, and the high speed of the diesel engine. The other is the assembled crankshaft, which is used for the large and medium sized ships and power generation with a low speed two stroke diesel engine. It is combined with the crankshaft and the shaft by hot pressing. Students can only watch general large crankshaft manufacturing process in a special manufacturer. It is difficult to launch in the school laboratories. Based on virtual reality technology, students can build a virtual simulation experiment of the entire manufacturing process from the forging to rough machining, finishing, assembly and testing of the crankshaft. In immersive virtual simulation environment, students can choose different processing method, control the simulation speed, adjust the angle of view and the visual range and analyze the processing effect of different working conditions and so on. Students not only learn every processing stage independently, but also learn complete the entire manufacturing process completely. Parts of the virtual simulation process are shown in Figure 2 to Figure 5.

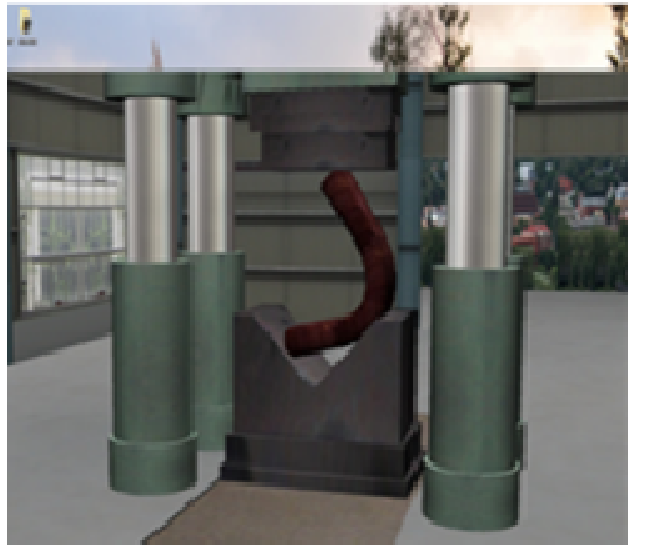

Fig. 2 forging process

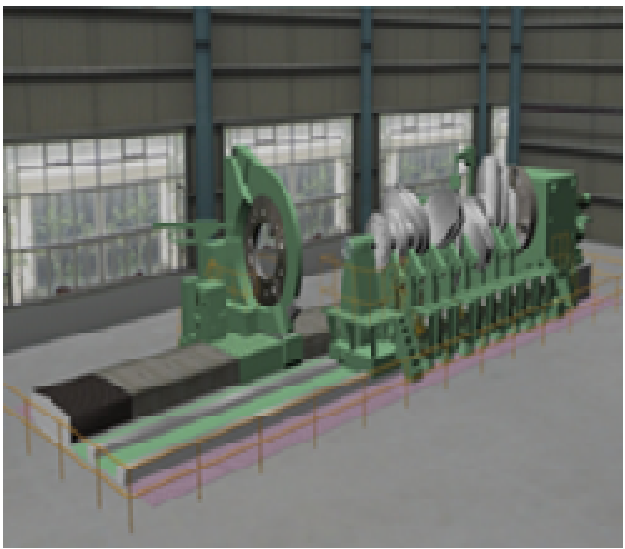

Fig. 3 cutting process 


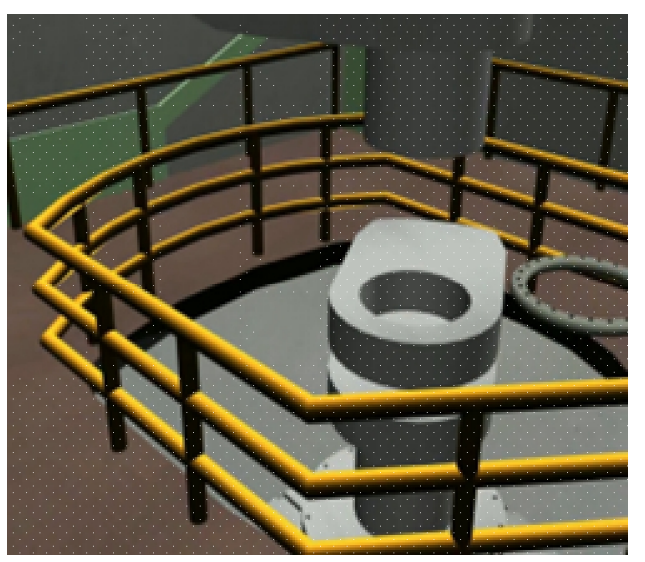

Fig. 4 assembly process simulation

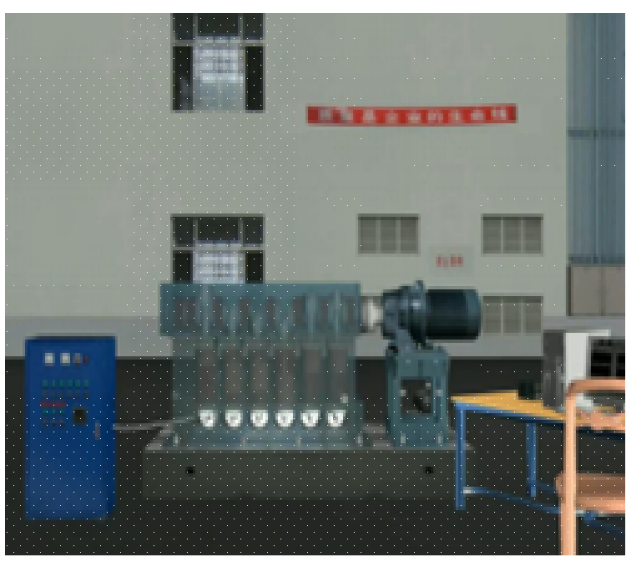

Fig. 5 testing process simulation

Digital Workshop Simulation Experiment. Digital workshop is a virtual manufacturing method, which is the core of manufacturing resources, production operation and products. Based on the digital product design data, digital workshop proceeds process of computer simulation and optimization of virtual manufacturing for the production in the existing real manufacturing system of the digital reality environment. Digital workshop technology adopts computer simulation and digital technology through group cooperative work supported on high performance computer and high speed network. It summarizes all aspects of objects of real manufacturing world and the modeling of activities and simulation research. The nature process of the product manufacturing containing product design, performance analysis, process planning, manufacturing, quality inspection, production process management and control can be achieved from the formation of the concept of the product, design to the manufacturing process of three-dimensional visual and interactive environment. The product function, performance machinability and possible problems can be simulated and predicted through computer digital model.

Through the digital workshop simulation experiment, students establish the overall understanding of the digital workshop, learn the production process of machinery manufacturing in enterprises, understand the contents of the workshop and the optimization method of the production process, and discuss the operation management mechanism of the digital workshop. In the virtual reality environment, students can analyze the equipment and auxiliary equipment and pipe network system, research whether the design of the production line meets the design of the logistics cycle and productivity, whether the cost of manufacturing meets the requirements, analyze production line layout, the use efficiency and manufacturing cost of the logistics bottleneck equipment. The students not only can learn details of specific steps, analyze interference the of the process of processing and other technical problems, but also check movement interference problems within equipment and equipment, and can assist equipment process planner to generate equipment processing instructions, and reproduce the real manufacturing process. Parts of the process of digital workshop layout simulation experiments are shown in figure 6 and figure 11: 


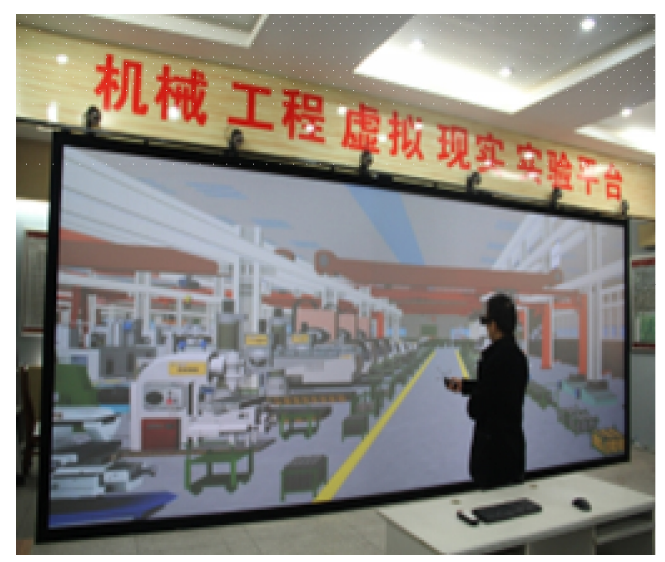

Fig. 6 virtual simulation platform of digital factory

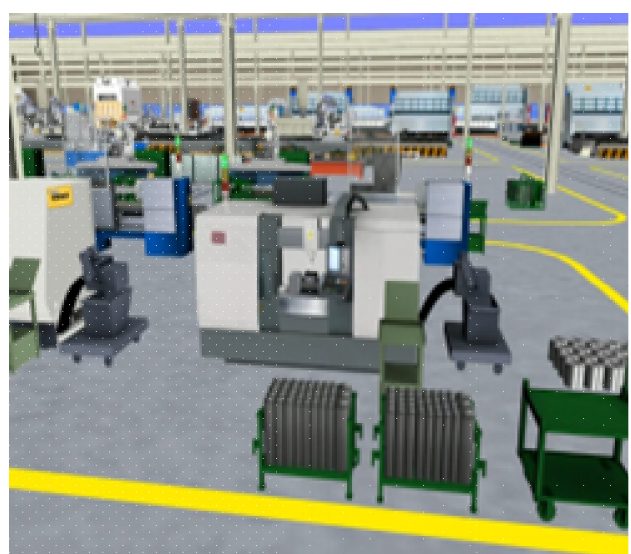

Fig. 8 Real-time monitoring equipment status

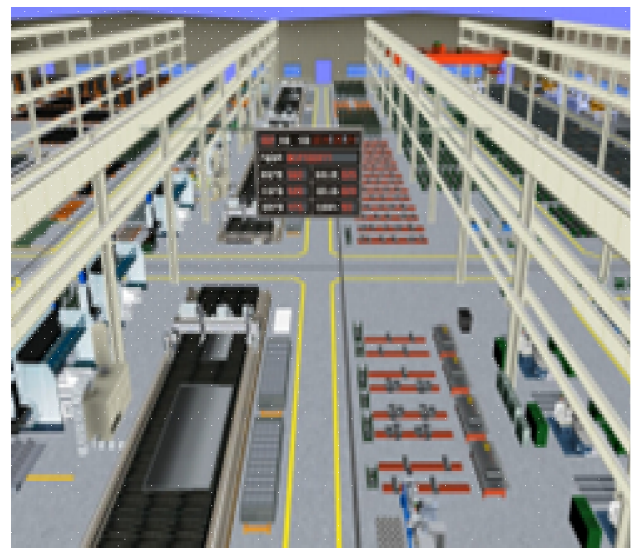

Fig. 10 kanban management system

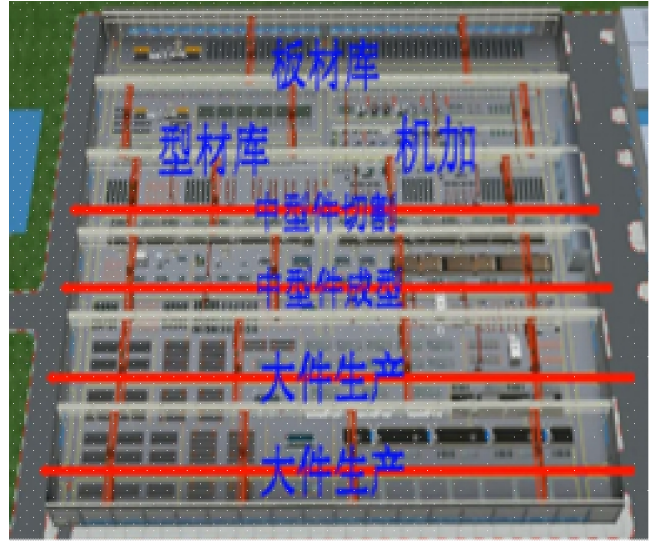

Fig. 7 the composition of digital workshop of a plate processing

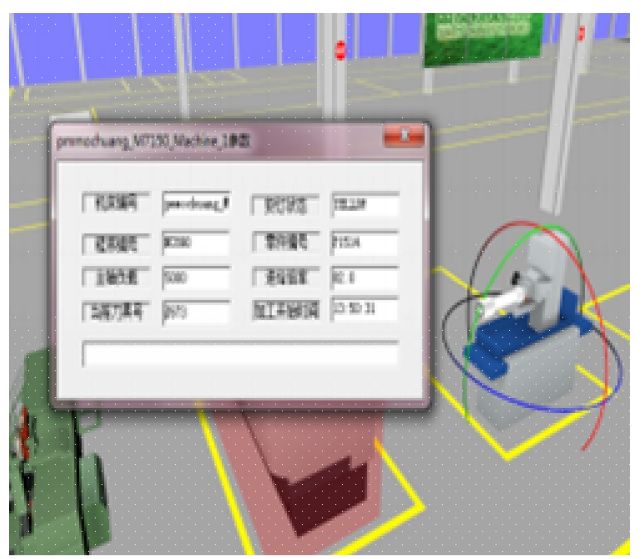

Fig. 9 Machine tool running status

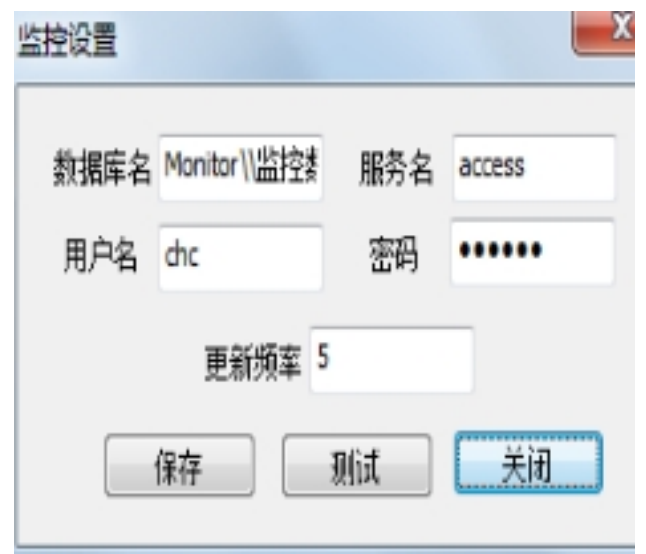

Fig. 11 monitor settings

\section{Conclusion}

Utilizing virtual simulation experiment teaching of virtual reality technology based on virtual reality technology, through the construction of immersive virtual learning scene, using a typical complete virtual manufacturing case, . Taking process of a digital factory simulation of mechanical manufacturing enterprise workshop layout and enterprise production as an example, using virtual manufacturing technology to achieve production of manufacturing, students can understand the process of information delivery among production line, workshop and factories and process from 
design to the actual manufacturing. Therefore learning interests of students and independent practice innovation learning ability have improved greatly.

\section{References}

[1] LI Ping, MAO Changjie, XU Jin. Construction of the National Virtual Simulation Experiment Teaching Centers, Improving the Experimental Teaching Informatization in Higher Education[J], Research and exploration in laboratory, Vol.32 No.11, 2013.11: 5-8.

[2] WANG Wei-guo. Construction Consideration and Suggestion of Virtual Simulation Experimental Teaching Center. Research and exploration in laboratory [J], Vol.32, No.12, 2013.12: 5-8.

[3] Fei Jingzhou, Zhang Peng, Ma Xiuzhen. Exploration on connotation construction of experimental teaching center of marine power technology[J], Experimental Technology and Management.Vol.31, No.6, 2014.5: 158-161.

[4] Cai Weiguo. Application of virtual simulation technology in mechanical engineering experimental teaching [J], Experimental Technology and Management, Vol.28, No.8, 2011.8: 76-82.

[5] HAN Zhi-xia, WEILiao-bo, HANHong-bo. Study and Practice on Imitative and Virtual Experiment Teaching [J]. Experimental Technology and Management, 2006, 23(2): 64-66.

[6] XIAO Tian-yuan, HAN Xiang-li, ZHANG Lin-xuan.Research on Virtual Manufacturing Technology and it’s Application. JOURNAL OF SYSTEM SIMULATION [J], Vol.13, No.12001, 01: 118-123.

[7] Wang Jinflin, Jiao Wei. Virtual reality technology and application [J]. Experimental Technology and Management, Vol. 20, No.12003: 58-61.

[8] MENG Yan-mei, QIN Gang-nian, LU Fu-ning. Designing the New Experimental Teaching System and Establishing a Mechanical Engineering Experimental Teaching Demonstration Center. [J]. Research and exploration in laboratory, 2009 (10): 23-26. 